\title{
Relationship between Family Environment and Mobile Phone Addiction among Young Adults
}

\author{
Shyam Sundar Sarma 1, Dr. Rita Rani Talukdar 2 \\ 1. (Dept of Psychology, Gauahati University, Assam, India.) \\ 2. (Dept of Psychology, Gauahati University, Assam, India.)
}

\begin{abstract}
The study attempts to investigate the relationship between family environment and mobile phone addiction among young adults. It was hypothesized that there would be no relationship between family environment and mobile phone addiction. Data were collected from a sample of $\mathrm{N}=80$ from young adults in Guwahati, Assam. Family Environment was measured by Family Environment Scale (Bhatia and Chaddha, 1993) and mobile phone addiction was measured by Mobile Phone Addiction Scale (Velayudhan and Srividya, 2012). The data were statistically treated and found a negative correlation between family environment and mobile phone addiction.
\end{abstract}

Keywords: Family Environment, Mobile Phone Addiction, Young Adults.

\section{INTRODUCTION}

With the explosive advancement of science and technology and growth in communication services, the mobile phone has becoming an important part of human life since the end of 20th century and researchers showing the avid interest in its impact on human life. At the beginning, the mobile phone was used as a status symbol or when necessary as the expenditure of using a mobile phone was very high. But in the late $20^{\text {th }}$ century, it had received a huge subscriber. Ling (2003) viewed; the mobile phone has fundamentally affected our society, accessibility, safety, and security, coordination of social and business activities and use of public places. It has just become the part of a culture of every region in the world. In the $21^{\text {st }}$ century, life without it is very difficult to imagine for some people, especially for youth. Ahmed (2004) said in a report of British Broadcasting Corporation (BBC) “Youth drives India's mobile phone revolution." In that report a girl's response added a value. The girl reported that she cannot imagine life without a mobile phone. The under $25 \mathrm{~s}$ are in a majority in India. They are mobile phone savvy."

So, it is undeniable that the number of people who cannot live without a cell phone is increasing. But a question has arisen: Why is the number of people who cannot live without a cell phone increasing? One of the reasons is the family environment.

\subsection{Key Concepts \\ 1.1.1 Family environment}

The term "family" refers to a variety of groupings including (1) a father, mother and their children, (2) children of father and mother, (3) a group of people living in the same house,(4) all of a person's relatives, (5) a group of related people, (a) a tribe, (7) one's ancestors (Adams, 1975; Blood, 1972; Winch, 1971).

According to Oxford Dictionary it is (a) the body of persons who live in one house with parents, children etc, (b) the ground consisting of parents and their children, (c) a person's children reared collectively, (d) those descended from a common ancestry. 
According to Maclver and Page, (2006). "The family environment is a group defined by sex relationship sufficiently precise and enduring to provide for the procreation and upbringing of children" while Clark (2007) said, "by family environment, we mean a system of relationship existing between Parents and children."

Family Environment basically mean :

1. The family is the main setting for the experiences of the child, particularly the young child.

2. The family is a dynamic set of relationships among all the people who live in the "family."

3. Children's behavior, ideas, thoughts, and fantasies affect the lives of those with whom they live.

4. The behavior, ideas, thoughts and fantasies of father and mother affect the lives of their children.

5. This group has resources that are used to adjust in life.

\subsubsection{Mobile Phone Addiction}

Mobile phone is the mostly used electronic device which is connected wirelessly to a network. According to the Oxford Advanced Learner's Dictionary, mobile phone is a telephone that does not have wires and works by radio that can be carry with to use everywhere. It is a device which is used by (mostly) every walk of life for several reasons. Some people use it as a way of personal communication. Its unique characteristics, such as affordability, accessibility and easy to carry; make it popular among the masses.

Social Influence, means behavior is influenced by other group of people, is also another reason to make it more popular. Also, mobile phone is primarily used for personal requirement and so, it gives a sense of Self, such as, "it belongs to me only."

Any extreme form of behavior is addictive (Peele, 1985). "Mobile phone addiction" is defined comparing with the conceptual dimensions of addictions cited in the Diagnostic and Statistical Manual of Mental Disorder-IVText Revision. These are as follows:

(a)Tolerance

(b) Withdrawal

(c)Using larger amounts or over a longer period than was intended

(d)The desire or unsuccessful efforts to cut down or control the substance use

(e)A great deal of time is spent in obtaining, using, or recovering from the substance

(f)Social, occupational, or recreational activities are reduced because of substance use, and

( $g$ )Substance use continues in spite of negative effects.

Bianchi \& Phillips (2005) viewed that persons with addiction to mobile phone exhibit some signs. Some of these are as follows:

1. They preoccupy themselves with the mobile phone,

2. They use the mobile phone for an increasing amount of time,

3. They fail to control,

4. They feel lost, restless, moody, depressed or irritable when attempting to cut down use of the mobile phone,

5. They hide from family and friends, or others to conceal the extent of involvement with the mobile phone; and

6. They use the mobile phone as a way of escape from problems or to relieve a dysphoric mood, e.g., feeling of isolation, anxiety, loneliness, and depression. 


\subsubsection{Young Adults}

The term adult is derived from a Latin word Adultus. It means "grown to the full size and strength." Therefore, adults are known as people who have completed growth and who become ready to assume their status in society. It is a period when one gets ready to pursue higher education, search for a job, and plan for future life. It is a period where one is assumed to be responsible, self-supporting and well integrated into society. In this study young adult refers to people who have achieved physical maturity.

\subsection{Operational definitions of other variables}

Relationship: In this study, relationship means the links between two variables.

Family environment: in this study, family environment refers to the dynamics of a family which influence the member of the family. In this study, a psychological scale, i.e. Family Environment Scale has been used and it has added value in defining it.

Mobile Phone Addiction: Mobile Phone Addiction is defined here as problematic uses of mobile phone. Mobile Phone Addiction Scale has added value in defining the mobile phone addiction.

Young Adult: Individuals whose age range from 20 to 22 years and who are pursuing graduation in regular mode of education.

\section{3: Conceptual Framework}

\subsubsection{Rationale of the study}

In a city life, the family type is basically neutral, though a few may live with their grandparents. But, the number of family member is a few and some may busy with their own jobs, careers etc and because of which they may not have enough time to share with the other members of the family. Young adults is the stage of life when an young adults needs to shoulder family relationship, needs to have a job etc and these life events cause stress. On the other hand, mobile phone is way to communicate with others, the collect information through the access to internet; sometimes it is a way to pass time also etc. That is why this study was conducted. It is hoped that this study will acquaint with the importance of family environment and the effects of mobile phone addiction.

1.3.2. Statement of the Problem:

Relationship between Family Environment and Mobile Phone Addiction among Young Adults.

\subsubsection{Objective}

To investigate the relationship between family environment and mobile phone addiction.

\subsubsection{Hypothesis}

There would be no relationship between family environment and mobile phone addiction.

\section{METHOD}

\subsection{Sample}

In this study, the sample size was 80 and among them 40 was male and 40 were female. Data were collected from different educational institutions located in Guwahati by using purposive sampling and based on the following inclusion criteria.

\subsection{Inclusion Criteria}

1. Young Adults (male-female) of 20-22 years of their chronological ages.

2. Young Adults pursuing graduation.

3. Young adults enrolled in regular mode of education.

4. Young adults who have been using mobile phone since at least one (1) year.

\subsection{Tools}

In this study two scales have been used. These are described below: 
2.3.1. Interview Schedule: A semi-structured questionnaire was constructed by the researchers to collect simple demographic information, such as name, sex, age, etc.

2.3.2. Family Environment Scale (FES): To measurement family environment Family Environment Scale (FES) which is developed and designed by Dr. Harpreet Bhatia and Dr. N.K. Chadha was used. This scale was published by Ankur Psychological Agency in 1993. Family Environment Scale is consisted of 69 items. These items were taken under three major dimensions. These are as follows:

1. Relationship Dimensions,

2. Personal Growth Dimensions, and

3. System Maintenance Dimensions.

Each dimension carried subscales. There are mentioned below:

The "Relationship Dimension" carried the following subscales:

1. Cohesion, 2. Expressiveness, 3. Conflict, and 4. Acceptance and Caring

As such, "Personal Growth Dimensions" carried the following sub-scales.

5. Independence and 6. Active Recreational Orientation

Under "System Maintenance Dimensions" following subscales have been found.

7. Organization and 8. Control

Reliability of FES: Split Half method was employed to find out the reliability of FES. But, the reliability coefficient of the entire scale was estimated by using Spearman -Brown Prophecy formula and the Reliability Coefficient of the FES was 0.95 .

Validity of FES: In this scale, Face validity and Content validity were tested.

2.3.3 Mobile Phone Addiction Scale: Mobile Phone Addiction Scale is designed by Dr. A. Velayudhan and Dr. S. Srividya and published by Prasad Psycho Corporation, in 2012. This scale was consisted of 37 items. To respond an item, five options were there and these items were fallen into six (6) subscales. These are cited below:
1. Maladaptive Usage
2. Self expression,
3. Peer Relationship
4. Interpersonal relations
5. Impulsivity,
6. Usage time

Reliability of MPAS: The reliability was tested by using Test-Retest method, especially through Cronbach's Alpha coefficient and it was found to be 0.79 . The Split Half reliability was found to be statistically significant at 0.75 . The internal consistency was found to be 0.89 .

Validity of MPAS: In this scale, Face validity and Criterion validity were tested. Criterion validity was determined by correlating with the 13 items Revised Cheek and Buss Shyness Scale (1983). The scale was correlated with UCLA Loneliness Scale, which was developed by Russell in 1996.

\subsection{Procedure}

At first, permission was taken from the authority of the college and the department for data collection. Then the researchers was allowed a particular date and students were also informed about it. Likewise, on the particular date, the researchers collected data.

At first, the purpose of the research, necessary instructions were given to the students and consent was obtained from the subjects. Secondly, demographic information was collected and Family Environment Scale was distributed. After completing the scale, 10 minutes rest was taken.

Thirdly, Mobile Phone Addiction Scale was distributed after given necessary instructions. Then, subjects were offered thanks for co-operation and subjects who had completed their questionnaire without leaving any statement unanswered were used for the study. 
III. RESULT AND DISCUSSION

The data were statistically treated by using SPSS and following results are found.

Table 1: Correlation between Family Environment and Mobile Phone Addiction

\begin{tabular}{|c|c|c|c|c|}
\hline & Mean & Std. Deviation & Pearson Correlation & N \\
\hline Family Environment & 254.15 & 30.47 & $-.355(* *)$ & 80 \\
Mobile Phone Addiction & 101.98 & 17.17 & & \\
\hline
\end{tabular}

** Correlation is significant at the 0.01 level (2-tailed) (Source: Primary data collected for the study)

This TABLE shows that the Mean values of Family Environment and Mobile Phone Addiction are 254.15 and 101.98 respectively. The Standard Deviations of Family Environment and Mobile Phone Addiction are 30.47 and 17.17 respectively. Then, the correlation between Family Environment and Mobile Phone addiction has found out. The correlation between Family Environment and Mobile Phone addiction is -.355, which is significant at the 0.01 level. That is negatively correlated and indicates that when Family Environment goes better, then the Mobile Phone Addiction level may decrease. If the Family Environment is congenial or good, it can be hoped that the children of the family would be able to control over Mobile Phone use.

Table 2: Correlation between Family Environment and Mobile Phone Addiction of Male respondents

\begin{tabular}{|c|c|c|c|c|}
\hline & Mean & Std. Deviation & Pearson Correlation & $\mathrm{N}$ \\
\hline $\begin{array}{c}\text { Family Environment } \\
\text { Mobile Phone Addiction }\end{array}$ & $\begin{array}{l}247.33 \\
105.45\end{array}$ & $\begin{array}{l}32.33 \\
17.39\end{array}$ & $-.454(* *)$ & 40 \\
\hline
\end{tabular}

This TABLE reveals that the Mean values of Family Environment and Mobile Phone Addiction of male respondents are 247.33 and 105.45 respectively. The Standard Deviations of Family Environment and Mobile Phone Addiction are 32.33 and 17.39. The correlation between Family Environment and Mobile Phone addiction for male is $-.454(* *)$, which is significant at the 0.01 level. It indicates that when the family environments of male respondents go better, their addiction level may decrease.

Table 3: Correlation between Family Environment and Mobile Phone Addiction of Female respondents

\begin{tabular}{|c|c|c|c|c|}
\hline & Mean & Std. Deviation & Pearson Correlation & $\mathrm{N}$ \\
\hline Family environment & 260.98 & 27.21 & -.162 & 40 \\
Mobile Phone Addiction & 98.50 & 16.43 & & \\
\hline
\end{tabular}

(Source: Primary data collected for the study)

TABLE 3 indicates that the Mean values of Family Environment and Mobile Phone Addiction for female respondents are 260.98 and 98.50 respectively. The Standard Deviations of Family Environment and Mobile Phone Addiction are 27.21 and16.43. The correlation between Family Environment and Mobile Phone addiction for female is -.162 which is negatively correlated but it is not significant. That means there is no significant relationship between family environment and mobile phone addiction. It shows that the female respondents may use their mobile phone controllably. 
Table 4: Gender wise group Statistics on Mobile Phone Addiction

\begin{tabular}{|c|c|c|c|c|c|}
\hline Gender & Mean & $\begin{array}{c}\text { Std. } \\
\text { Deviation }\end{array}$ & $\mathrm{t}$ & $\mathrm{df}$ & $\begin{array}{c}\text { Sig. (2- } \\
\text { tailed) }\end{array}$ \\
\hline Male & 105.45 & 17.39 & \multirow{2}{*}{1.837} & 78 & .070 \\
\hline Female & 98.50 & 16.43 & & \\
\hline
\end{tabular}

(Source: Primary data collected for the study)

This table is to find out the difference between male and female on their mobile phone addiction. It shows the Mean values of mobile phone addiction of male and female are 105.45 and 98.50 respectively. The Standard deviations between male and female are 17.39 and 16.43 respectively. The t value is 1.837 which is not significant but the addiction level of the male respondents is higher than the female respondents which suggest that the female respondents were lesser addicted than male. There may have a psychological reason that though females also have addiction, but they may engage in their own personal work, household works etc., or they may have better skills to maintain both family and personal life along with mobile phone use.

\section{FINDINGS}

Finally this study showed the following:

1. When Family Environment goes better of the participants, then the Mobile Phone Addiction level may decrease. If the Family Environment is congenial or good, it can be hoped that the children of the family would be able to control over Mobile Phone use.

2. When the family environments of male respondents go better, their addiction level may decrease. Regarding administration on male respondent, if parents be a good administrator, it may control the mobile phone addiction for their children.

3. There is no significant relationship between family environment and mobile phone addiction of female participants. It shows that the female respondents may use their mobile phone controllably.

4. The female respondents were lesser addicted to mobile phone than male participants. There may have a psychological reason that though females also have addiction, but they may engage in their own personal work, household works etc., or they may have better skills to maintain both family and personal life along with mobile phone use.

\section{CONCLUSION}

Finally, this study brought out an understanding between family environment and mobile phone addiction among young adults. It revealed that the family environment is related to mobile phone addiction among the young adults. But, to have, wider understanding, the sample size should be increased.

\section{REFERENCES}

[1] Ahmed, Z (2004). Youth drives India's mobile phone revolution.

Retrieved from http://news.bbc.co.uk/2/hi/business/3585257.stm

[2] American Psychiatric Association. (2000). Diagnostic and statistical manual of mental disorder (4 ${ }^{\text {th }}$ ed.,

Text Revision). Wilson Boulevard, Arlington, VA: author. 
[3] Bhatia, H. \& Chadha, N. K. (1993). Manual for family environment scale. Lucknow: Ankur Psychological Agency.

[4] Bianchi, A. and Phillips, J.G. (2005). Psychological predictors of problem mobile phone use. Cyber psychology \& behavior, 8(1), 39-51.

[5] Blood, R.O. (1972). The family. New York: Free Press.

[6] Hurlock, E. B. (2007). Developmental psychology: A life span approach (5 ${ }^{\text {th }}$ ed.). New Delhi: Tata McGraw-Hill Publishing Company Limited.

[7] Javid,M., Malik, M.A., \& Gujjar, A.A. (2011, February). Mobile phone culture and its psychological impacts on students' learning at the university level. Language in India: Strength for Today and Bright Hope for Tomorrow, 11(2), 415-422.

[8] Kaur, M. (2014, June). Family environment as a determinant of behaviour orientation among adolescents of Bathinda district. The International Journal of Humanities \& Social Studies, 2(6), 1-9.

[9] Ling, R. (2003).The mobile connection ( $3^{\text {rd }}$ ed.). New York: Morgan Kaufmann Publishing Co.

[10] Morgan, C. T., King, R. A., Weisz, J. R., \& Schopler, J. (2006). Introduction to psychology (7th ed.). New Delhi: Tata McGraw-Hill Publishing Company Limited.

[11] Myers, D.G. (1999). Exploring Psychology (4th ed.). New Work: Worth Publishers.

[12] Turnbull, J., Lea, D., Parkison, D., Phillips, P. Francis, B., Webb, S. \& Bull, V. (2010). Oxford Advanced Learner's Dictionary. London: Oxford University Press.

[13] Peele, S. (1985). The meaning of addiction. Compulsive experience and its interpretation. Lexington: Lexington Books.

[14] Vohra, S. (1998). Manual for family environment scale. New Delhi: PSY.COM Services.

[15] Paul, L. (2000). Cell phone, (1st ed.). New York: Palgrove publishers.

[16] Passer, M.W., Smith. R. E., Atkinson, M. L., Mitchell, J. B., \& Muir, D.W. (2003). Psychology frontiers and application (1st Canadian ed.). Canada: McGraw-Hill Ryerson.

[17] Reber, A. S., Allen, R., \& Reber, E. S. (2009) Penguin dictionary of psychology (4th ed.). England: Penguin Books Limited.

[18] Tiwari, G. Abnormal psychology: A Dynamic Approach. Agra-2: Vinod Pustak Mandir.

[19] Velayudhan, A. \& Srividya, S. (2012). Manual for mobile phone addiction scale. New Delhi: Prasad Psycho Corporation.

[20] Winch, R.F. (1971). The modern family ( $3^{\text {rd }}$ ed.). New York: Holt. 